BMJ Open

Diabetes

Research

\& Care

\title{
Diabetes risk score in the United Arab Emirates: a screening tool for the early detection of type 2 diabetes mellitus
}

\author{
Nabil Sulaiman, ${ }^{1}$ Ibrahim Mahmoud, ${ }^{1}$ Amal Hussein, ${ }^{1}$ Salah Elbadawi, ${ }^{2}$ \\ Salah Abusnana, ${ }^{1,3}$ Paul Zimmet, ${ }^{4}$ Jonathan Shaw ${ }^{5}$
}

To cite: Sulaiman $N$, Mahmoud I, Hussein A, et al. Diabetes risk score in the United Arab Emirates: a screening tool for the early detection of type 2 diabetes mellitus. BMJ Open Diab Res Care 2018;6:e000489. doi:10.1136/ bmjdrc-2017-000489

Received 24 October 2017 Revised 14 February 2018 Accepted 14 March 2018
A) Check for updates

${ }^{1}$ College of Medicine, University of Sharjah, Sharjah, United Arab Emirates

${ }^{2}$ Dubai Health Authority, Dubai, United Arab Emirates

${ }^{3}$ Rashid Center for Diabetes and Research, Ajman, United Arab Emirates

${ }^{4}$ Monash University, Melbourne, Victoria, Australia

${ }^{5}$ Baker IDI Heart \& Diabetes Institute, Melbourne, Victoria, Australia

Correspondence to Dr Ibrahim Mahmoud; tabat214@gmail.com

\section{ABSTRACT}

Objective The objective of this study was to develop a simple non-invasive risk score, specific to the United Arab Emirates (UAE) citizens, to identify individuals at increased risk of having undiagnosed type 2 diabetes mellitus. Research design and methods A retrospective analysis of the UAE National Diabetes and Lifestyle data was conducted. The data included demographic and anthropometric measurements, and fasting blood glucose. Univariate analyses were used to identify the risk factors for diabetes. The risk score was developed for UAE citizens using a stepwise forward regression model.

Results A total of 872 UAE citizens were studied. The overall prevalence of diabetes in the UAE adult citizens in the Northern Emirates was $25.1 \%$. The significant risk factors identified for diabetes were age ( $\geq 35$ years), a family history of diabetes mellitus, hypertension, body mass index $\geq 30.0$ and waist-to-hip ratio $\geq 0.90$ for males and $\geq 0.85$ for females. The performance of the model was moderate in terms of sensitivity $(75.4 \%, 95 \% \mathrm{Cl} 68.3$ to $81.7)$ and specificity $(70 \%, 95 \% \mathrm{Cl} 65.8$ to 73.9$)$. The area under the receiver-operator characteristic curve was 0.82 (95\% Cl 0.78 to 0.86).

Conclusions A simple, non-invasive risk score model was developed to help to identify those at high risk of having diabetes among UAE citizens. This score could contribute to the efficient and less expensive earlier detection of diabetes in this high-risk population.

\section{INTRODUCTION}

The prevalence of type 2 diabetes (T2D) is increasing in nearly all populations worldwide. ${ }^{1}$ The United Arab Emirates (UAE) has one of the world's highest prevalence rates of T2D of $18.7 \%$ and is expected to reach $21.4 \%$ by $2030 .^{2}$

It has been well known that T2D is a major risk factor for premature mortality and serious complications such as heart attack, stroke, blindness, amputation and kidney failure. ${ }^{34}$ These cause a large burden to the patients, their families and the healthcare system. ${ }^{3}{ }^{4}$ A number of studies have shown that type 2 diabetes and its complications can be prevented or delayed by implementing lifestyle modifications or using pharmacological

\section{Key messages \\ What is already known about this subject? \\ - The United Arab Emirates (UAE) has one of the world's highest prevalence rates of type 2 diabetes mellitus (T2D). \\ - Risk scores to identity individuals at high risk of T2D have been developed for other nations. \\ What are the new findings? \\ - This study provides a risk score specific and appropriate to UAE citizens. \\ How might these results change the focus of research or clinical practice? \\ - Early detection of T2D in UAE citizens might allow an early intervention and reduces its complications.}

treatment. ${ }^{5}{ }^{6}$ Therefore, identifying individuals with current undiagnosed diabetes or those at high risk of developing T2D in the future is of great importance in reducing the burden of diabetes and its complications. ${ }^{78}$

In this context, several researchers have already developed risk assessment tools for other nations based on simple routinely collected information and anthropometric measures to predict the risk of having undetected diabetes before sending individuals for blood tests. ${ }^{9-13}$ However, these risk tools may not be useful or appropriate to the UAE population due to differences in lifestyle and ethnicity.

The aim of this study was to develop a simple, non-invasive, self-administered and informative risk score system appropriate for UAE citizens to identify individuals at high risk of having undiagnosed diabetes.

\section{METHODS}

\section{Study design and settings}

The study accessed data from the UAE National Diabetes and Lifestyle Study. The UAE National Diabetes and Lifestyle Study 
is a cross-sectional survey designed to investigate the prevalence of diabetes and associated risk factors among UAE citizens and expatriates. The data were collected in two phases. In the first phase, non-UAE citizen adults (including our validation sample of Arab non-UAE citizens) who had lived in the UAE for at least 4 years were surveyed. In the second phase, data were collected from UAE citizens. The survey was

\begin{tabular}{|c|c|c|c|}
\hline Variable & No diabetes, n (\%) & Diabetes, n (\%) & $P$ value \\
\hline \multicolumn{4}{|l|}{ Sex } \\
\hline Female & $320(49.0)$ & $103(47.0)$ & \multirow[t]{2}{*}{0.613} \\
\hline Male & $333(51.0)$ & $116(53.0)$ & \\
\hline \multicolumn{4}{|l|}{ Age, years } \\
\hline $18-34$ & $219(33.5)$ & $20(9.13)$ & \multirow[t]{3}{*}{0.001} \\
\hline $35-64$ & $416(63.7)$ & $164(74.8)$ & \\
\hline$\geq 65$ & $18(2.8)$ & $35(16)$ & \\
\hline \multicolumn{4}{|l|}{ Education } \\
\hline Did not complete secondary school & $89(13.7)$ & $89(45.2)$ & \multirow[t]{3}{*}{0.189} \\
\hline Completed secondary school & $296(45.6)$ & $66(33.5)$ & \\
\hline Tertiary education & $264(40.7)$ & $42(21.3)$ & \\
\hline \multicolumn{4}{|l|}{ Income, year (AED) } \\
\hline$\leq 35999$ & $147(27.3)$ & $48(30)$ & \multirow[t]{3}{*}{0.260} \\
\hline $36000-179999$ & $128(23.7)$ & $43(26.9)$ & \\
\hline$\geq 180000$ & $264(49)$ & $69(43.1)$ & \\
\hline \multicolumn{4}{|l|}{ Regions } \\
\hline Sharjah & $329(50.4)$ & $111(50.7)$ & \multirow[t]{5}{*}{0.174} \\
\hline Umm al-Quwain & $73(5.7)$ & $16(7.3)$ & \\
\hline Ras al-Khaimah & $204(31.2)$ & $32(19.2)$ & \\
\hline Fujairah & $45(6.9)$ & $29(13.2)$ & \\
\hline Ajman & $38(5.8)$ & $21(9.6)$ & \\
\hline \multicolumn{4}{|l|}{ Smoking status } \\
\hline No & $533(87.9)$ & $161(86.1)$ & \multirow[t]{2}{*}{0.902} \\
\hline Yes & $76(12.1)$ & $26(13.9)$ & \\
\hline \multicolumn{4}{|l|}{ Moderate regular physical activity } \\
\hline No & $573(89.5)$ & $184(90.2)$ & \multirow[t]{2}{*}{0.786} \\
\hline Yes & $67(10.5)$ & $20(9.8)$ & \\
\hline \multicolumn{4}{|c|}{ Family history of diabetes mellitus (parents/siblings) } \\
\hline No & $501(78.3)$ & $74(34.3)$ & \multirow[t]{2}{*}{0.030} \\
\hline Yes & $139(21.7)$ & $142(65.7)$ & \\
\hline \multicolumn{4}{|l|}{ Hypertension status } \\
\hline No & $543(84.4)$ & $104(49.6)$ & \multirow[t]{2}{*}{$<0.001$} \\
\hline Yes & $100(15.6)$ & $110(51.4)$ & \\
\hline \multicolumn{4}{|l|}{ Body mass index, $\mathrm{kg} / \mathrm{m}^{2}$} \\
\hline$<25$ & $184(28.4)$ & $30(13.9)$ & \multirow[t]{3}{*}{$<0.001$} \\
\hline $25-29$ & $244(37.8)$ & $72(33.3)$ & \\
\hline$\geq 30.0$ & $219(33.8)$ & $114(52.8)$ & \\
\hline \multicolumn{4}{|l|}{ Waist-to-hip ratio } \\
\hline$<0.90$ for males and $<0.85$ for females & $232(63.5)$ & $41(19.4)$ & \multirow[t]{2}{*}{$<0.001$} \\
\hline$\geq 0.90$ for males and $\geq 0.85$ for females & $403(36.5)$ & $170(80.6)$ & \\
\hline
\end{tabular}

AED, United Arab Emirates Dirham. 
Table 2 Univariate regression analysis of the risk factors for undiagnosed type 2 diabetes

\begin{tabular}{|c|c|c|}
\hline Variable & OR $(95 \% \mathrm{Cl})$ & $P$ value \\
\hline \multicolumn{3}{|l|}{ Gender } \\
\hline Female & 1 & \\
\hline Male & 1.01 (0.72 to 1.60$)$ & 0.763 \\
\hline \multicolumn{3}{|l|}{ Age, years } \\
\hline 18-34 & 1 & \\
\hline $35-64$ & 2.70 (1.91 to 5.39$)$ & 0.047 \\
\hline$\geq 65$ & 5.19 (2.47 to 10.89$)$ & $<0.001$ \\
\hline \multicolumn{3}{|c|}{ Family history of diabetes mellitus (parents/siblings) } \\
\hline No & 1 & \\
\hline Yes & 3.37 (2.26 to 5.03$)$ & $<0.001$ \\
\hline \multicolumn{3}{|l|}{ Smoking status } \\
\hline No & 1 & \\
\hline Yes & $1.18(0.68$ to 2.04$)$ & 0.566 \\
\hline \multicolumn{3}{|c|}{ Moderate regular physical activity } \\
\hline No & 1 & \\
\hline Yes & $0.93(0.55$ to 1.57$)$ & 0.786 \\
\hline \multicolumn{3}{|l|}{ Hypertension status } \\
\hline No & 1 & \\
\hline Yes & 1.48 (1.04 to 2.18$)$ & 0.049 \\
\hline \multicolumn{3}{|l|}{ Body mass index, $\mathrm{kg} / \mathrm{m}^{2}$} \\
\hline$<25$ & 1 & \\
\hline 25.0-29.9 & 1.81 (1.14 to 2.89 ) & 0.013 \\
\hline$\geq 30.0$ & 3.19 (2.04 to 5.00$)$ & $<0.001$ \\
\hline \multicolumn{3}{|l|}{ Waist-to-hip ratio } \\
\hline $\begin{array}{l}<0.90 \text { for males } \\
\text { and }<0.85 \text { for females }\end{array}$ & 1 & \\
\hline $\begin{array}{l}\geq 0.90 \text { for males and } \\
\geq 0.85 \text { for females }\end{array}$ & 2.39 (1.64 to 3.48$)$ & $<0.001$ \\
\hline
\end{tabular}

conducted during 2013 in Sharjah and the Northern Emirates.

\section{Participants}

We used the data collected in the second phase of the UAE National Diabetes and Lifestyle Study, which include only UAE citizens, aged 18 years and above. People with previously diagnosed diabetes, serious physical disabilities, learning disorders, severe communication barriers and pregnant women were excluded from the analysis.

\section{Variables}

The variables considered included demographic (eg, gender, age, geographic location), family history of diabetes and lifestyle habits. Anthropometric measurements (weight, height and waist and hip circumferences), and systolic and diastolic blood pressure were obtained. In addition, a fasting blood samples were assayed for blood glucose and glycated hemoglobin (HbA1c).

\section{Data sources/measurement}

The UAE National Diabetes and Lifestyle Study collected data from adult residents living in the Northern Emirates (Sharjah, Ajman, Ras al-Khaimah, Fujairah and Umm al-Quwain). Participants were recruited via a household survey of non-institutionalized adults, following a random selection of districts, and stratified by emirate using a cluster sampling method. The methods are described in detail elsewhere. ${ }^{14}$

Diabetes status was based on an HbAlc test. Cut-off values for the test were defined according to the WHO criteria, whereby $<6.5 \%$ was considered non-diabetic and $\geq 6.5 \%$ indicated diabetes. ${ }^{15}{ }^{16}$ A family history of diabetes was defined as a parent or a sibling with diabetes. Body mass index (BMI) was calculated by dividing a participant's weight in kilograms by his/her squared height in meters and placing participants into three categories $\left(<25,25-29.9\right.$ and $\left.\geq 30 \mathrm{~kg} / \mathrm{m}^{2}\right)$. The waist-to-hip ratio was calculated as the waist circumference divided by the hip circumference. A waist-to-hip ratio $<0.90$ for males and $<0.85$ for females was considered normal. Hypertension was defined as a self-report diagnosis and/or blood pressure $\geq 140 / 90 \mathrm{~mm} \mathrm{Hg}$.

\section{Statistical analysis}

To describe the demographic and clinical characteristics of the population, we reported frequencies with proportions for people with diabetes and people without diabetes.

Univariate analyses were conducted to identify the significant risk factors. The non-significant variables were eliminated. Statistical significance was set at $\mathrm{P}<0.05$.

Stepwise forward logistic regression modeling was used to develop the score, with diabetes status (yes/no) as the dependent variable. The Omnibus Tests of Model Coefficients showed that the multivariate logistic regression models were statistically significant. The casewise plots were not produced because no outliers were found and no multicollinearity detected (variance inflation factor $<3)$.

For each significant variable in the multiple logistic regression analysis, a score was calculated by multiplying the regression coefficients by 10 and rounding to the nearest integer. The risk score for an individual patient was determined by adding the score for each variable in the risk model.

A receiver-operating characteristic (ROC) curve and the area under the curve (AUC) were used to evaluate the risk score developed and to determine a cut-off for our population based on maximizing a sum of sensitivity and specificity.

Data from Arab non-UAE citizens living in the UAE (phase I) were used to assess the validity of the UAE citizens' risk score $(\mathrm{n}=631)$.

The data analysis was performed with the Statistical Package for Social Sciences (SPSS) V.22 (IBM, New York, USA). Reporting followed the Strengthening the 


\begin{tabular}{|c|c|c|c|c|}
\hline Variable & $\beta$-Coefficient & OR $(95 \% \mathrm{Cl})$ & $P$ value & Score \\
\hline \multicolumn{5}{|l|}{ Age, years } \\
\hline $18-34$ & Reference & 1 & & 0 \\
\hline $35-64$ & 0.424 & 1.75 (1.10 to 3.38$)$ & 0.037 & 4 \\
\hline$\geq 65$ & 1.017 & 3.38 (2.23 to 5.12$)$ & $<0.001$ & 10 \\
\hline \multicolumn{5}{|c|}{ Family history of diabetes mellitus (parents/siblings) } \\
\hline No & Reference & 1 & & 0 \\
\hline Yes & 0.734 & 2.08 (1.47 to 2.96$)$ & $<0.001$ & 7 \\
\hline \multicolumn{5}{|l|}{ Hypertension status } \\
\hline No & Reference & 1 & & 0 \\
\hline Yes & 0.389 & 1.48 (1.04 to 2.18$)$ & 0.050 & 4 \\
\hline \multicolumn{5}{|l|}{ Body mass index, $\mathrm{kg} / \mathrm{m}^{2}$} \\
\hline$<25$ & Reference & 1 & & 0 \\
\hline $25.0-29.9$ & 0.129 & 1.14 (0.67 to 1.94$)$ & 0.637 & 0 \\
\hline$\geq 30.0$ & 0.676 & 1.97 (1.17 to 3.30$)$ & 0.011 & 7 \\
\hline \multicolumn{5}{|l|}{ Waist-to-hip ratio } \\
\hline$<0.90$ for males and $<0.85$ for females & Reference & 1 & & 0 \\
\hline$\geq 0.90$ for males and $\geq 0.85$ for females & 0.534 & 1.71 (1.08 to 2.69$)$ & $<0.001$ & 5 \\
\hline Cut-off point & & & & $\geq 19$ \\
\hline
\end{tabular}

A score for each variable in the model was calculated by multiplying the $\beta$-coefficient by 10 and to the nearest integer. A score of $\geq 19$ points indicated a high risk for having diabetes.

Reporting of Observational Studies in Epidemiology statement for cross-sectional studies.

\section{RESULTS}

Of the 872 participants in the study, $449(51.5 \%)$ were male, and the mean was age 42.8 (SD 13.4) years. The crude prevalence of total diabetes in the Emirati adult population in the Northern Emirates was $25.1 \%$. The prevalence of undiagnosed diabetes was $14.8 \%$. Table 1 describes the sociodemographic, medical history and anthropometric characteristics of the study participants. The risk factors for undetected diabetes were evaluated using univariate regression analysis (table 2). Gender, income, education and smoking status were not statistically significantly associated with the presence of diabetes $(\mathrm{P}>0.05)$, and were, therefore, excluded from our final model (table 2).

The variables included in the final logistic regression model were age ( $<35$ vs $\geq 35$ years) (OR $3.38,95 \%$ CI 2.23 to 5.12), a family history of diabetes (OR $2.08,95 \% \mathrm{CI}$ 1.47 to 2.96$)$, BMI $\left(\mathrm{kg} / \mathrm{m}^{2}\right)$ (OR $1.97,95 \%$ CI 1.17 to 3.30 ) and hypertension (OR $1.48,95 \%$ CI 1.04 to 2.18 ), after stepwise forward modeling ( $>0.05)$ (table 3$)$. The risk score for each variable in the model was calculated by multiplying the $\beta$-coefficient by 10 and to the nearest integer(table 3).

The performance of our model is shown in figure 1 , with an AUC of $0.82,95 \%$ CI 0.78 to 0.86 . The model revealed a moderate sensitivity of $75.4 \%, 95 \%$ CI 68.3 to 81.7 and specificity $70 \%, 95 \%$ CI 65.8 to 73.9 , with an optimum cut-off $\geq 19$ points to identify risk of having diabetes (table 4 ).

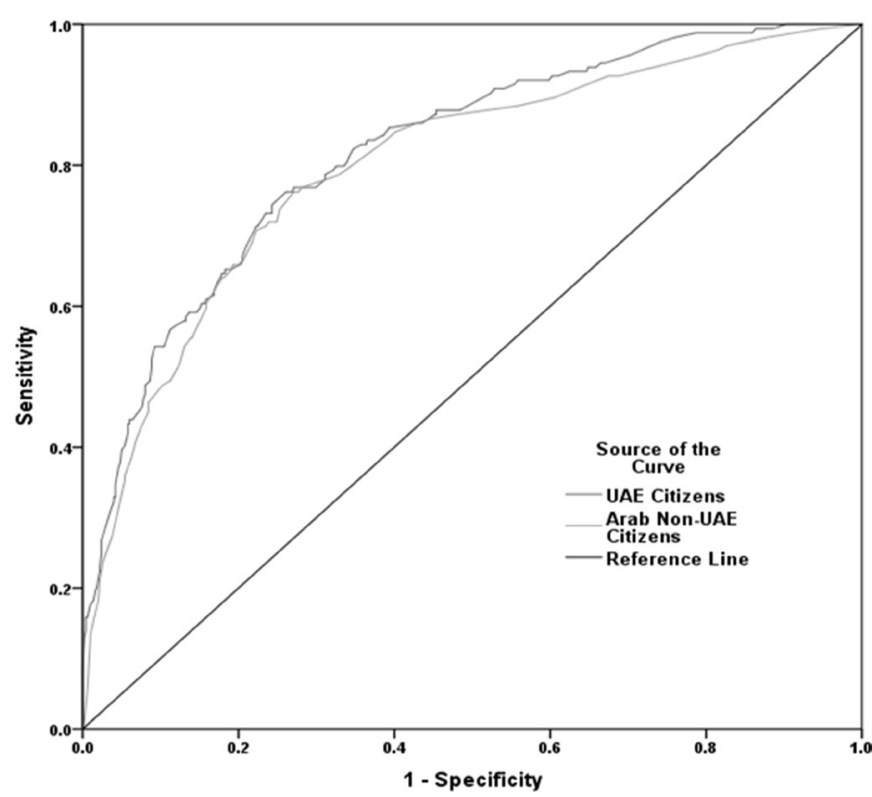

Figure 1 Receiver-operating characteristic curves showing the performance of the diabetes risk score in predicting diabetes in the United Arab Emirates (UAE) citizens (area under the curve (AUC) $=0.82,95 \% \mathrm{Cl} 0.78$ to 0.86$)$ and Arab non-UAE citizens ( $A \cup C=0.80,95 \% \mathrm{Cl} 0.76$ to 0.84 ). 
Table 4 Performance characteristics of the non-invasive risk score for type 2 diabetes in the primary and validation cohorts

\begin{tabular}{lllllll}
\hline Model & AUC & $\begin{array}{l}\text { Cut- } \\
\text { off }\end{array}$ & $\begin{array}{l}\text { Sensitivity } \\
\%(\mathbf{9 5 \%} \text { CI) }\end{array}$ & $\begin{array}{l}\text { Specificity } \\
\%(\mathbf{9 5 \%} \text { CI) }\end{array}$ & PPV & NPV \\
\hline UAE citizens & $0.82(0.78-0.86)$ & $\geq 19$ & $75.4(68.3$ to 81.7$)$ & $70.0(65.8$ to 73.9$)$ & $45.3(39.4-51.2)$ & $89.6(86.2-92.4)$ \\
Arab non-UAE citizens & $0.80(0.76-0.84)$ & $\geq 15$ & $74.4(67.7$ to 80.3$)$ & $71.5(67.7$ to 75.1$)$ & $46.1(40.6-51.7)$ & $89.5(86.4-92.1)$ \\
\hline
\end{tabular}

AUC, area under the curve; NPV, negative predictive value; PPV, positive predictive value; UAE, United Arab Emirates.

\section{Model validation}

We assessed the validity of this risk score on data collected from the non-citizen Arabs in first phase of the UAE National Diabetes and Lifestyle Study. We have chosen the data for the Arab population residing in the UAE because of their similarities with UAE citizens. Of the 631 Arab non-UAE citizens (validation sample), 455 (72\%) were male, with a mean age of 38 (SD 11) years. The risk score model performed very similarly in the validation sample with a minimal decrease in the AUC value $(0.80)$ and sensitivity $(74.4 \%)$ and a minimal increase in the specificity $(71.5 \%$ ) (table 4$)$. The cut-point, based on maximizing the sum of sensitivity and specificity, for diabetes was higher for the UAE citizens $(\geq 19)$ than for Arab non-UAE citizens $(\geq 15)$.

\section{DISCUSSION}

Our study findings indicated a high prevalence of diabetes among UAE citizens who live in the Northern Emirates $(25.1 \%)$ higher than what was suggested by previous studies in UAE citizens. ${ }^{12}$ Furthermore, the latest figures suggested that the Gulf region has high risk factors for T2D, with the UAE performing the worst. ${ }^{9} 1718$

We developed a scoring system to predict the presence of undiagnosed diabetes among adult UAE citizens. The risk factors identified from the univariate analysis were similar to those reported in earlier studies, and include self-reported demographic and behavioral factors, medical history and anthropometric measures. ${ }^{9-13}$ The model included risk factors that could be obtained by self-report or measured by a health professional without the need for a blood sample. The significant risk factors identified in our model are age ( $\geq 35$ years), a family history of diabetes (parents or siblings), blood pressure status, a BMI $\geq 30$ and waist-to-hip ratio $\geq 0.90$ for males and $\geq 0.85$ for females.

Our scores showed moderate sensitivity and specificity in detecting undiagnosed diabetes. Therefore, this non-invasive model could be used to identify individuals at high risk of developing diabetes within the Emirati population. It provides a safe, inexpensive and easy self-administered tool for screening.

Compared with other studies conducted in the region (Kuwait, Saudi Arabia and Oman), ${ }^{9} 1719$ the results are quite similar in terms of performance and the numbers of risk factors evaluated. Furthermore, the Saudi study had a similar sensitivity to our study $(76.6 \%)$, yet poor specificity $(52.1 \%)$. Interestingly, the Saudi study included women with gestational diabetes in their model unlike most other risk scores. However, the authors did not mention whether they adjusted for gender in their model; in particular, they had a high number of males in their sample (62\%). In addition, smoking was given the lowest point value in the Saudi Diabetes Risk Score. However, smoking did not contribute to our score. This is consistent with some of previously developed diabetes risk scores. ${ }^{9} 1120$

The Kuwaiti model had higher sensitivity $(87 \%)$ than our study but lower specificity (64\%). The Omani risk score model performance varied, with sensitivity ranging between $78.6 \%$ and $62.8 \%$ and specificity between $73.4 \%$ and $78.2 \%$. The risk factors identified by both Kuwaiti and Omani models were nearly identical to our model. In all models from the Gulf region, including that for the UAE, gender was not a component. This is different from studies from other regions such as Europe and Asia. ${ }^{11} 2021$

There were several limitations to our study. First, it is based on residents in the Northern Emirates, which might not be representative of the overall UAE population. In addition, the higher prevalence of diabetes in some Emirates with unbalanced age distribution might mean that larger studies of these populations should be performed. Second, the data were not collected for this analysis, specifically. Third, we did not have another Emirati population on which to validate the score, although we believe that the non-citizen Arabs are a good proxy, although we note a male predominance in the Arab population (72\%), which influences its generalizability. Finally, dietary intake was not included in our models. Studies have shown that diet and exercise interventions can significantly reduce the incidence of diabetes. ${ }^{5622}$

\section{CONCLUSION}

This study developed a risk score model that is specifically designed and appropriate for UAE citizens to assess diabetes risk. It offers a non-invasive, inexpensive and safe tool for screening to identify Emiratis at high risk of having undiagnosed diabetes.

Contributors NS, JS, PZ, SA, AH and SE planned and designed this study. IM performed data management and data analysis and all authors interpreted the data. All authors drafted the manuscript and approved the final version of the manuscript. PZ and JS revised the paper critically for important intellectual content. Funding This work was supported by Ministry of Health and Prevention, University of Sharjah and Sanofi (grant number 120301).

Competing interests None declared.

Patient consent Obtained. 
Ethics approval University of Sharjah and the Ministry of Health Research Ethics Committee.

Provenance and peer review Not commissioned; externally peer reviewed. Data sharing statement Data from the UAE National Diabetes and Lifestyle Study can be obtained by writing a proposal to Professor Nabil Sulaiman.

Open Access This is an Open Access article distributed in accordance with the Creative Commons Attribution Non Commercial (CC BY-NC 4.0) license, which permits others to distribute, remix, adapt, build upon this work non-commercially, and license their derivative works on different terms, provided the original work is properly cited and the use is non-commercial. See: http://creativecommons.org/ licenses/by-nc/4.0/

(C) Article author(s) (or their employer(s) unless otherwise stated in the text of the article) 2018. All rights reserved. No commercial use is permitted unless otherwise expressly granted.

\section{REFERENCES}

1. Ogurtsova K, da Rocha Fernandes JD, Huang Y, et al. IDF diabetes atlas: global estimates for the prevalence of diabetes for 2015 and 2040. Diabetes Res Clin Pract 2017;128:40-50.

2. Shaw JE, Sicree RA, Zimmet PZ. Global estimates of the prevalence of diabetes for 2010 and 2030. Diabetes Res Clin Pract 2010;87:4-14.

3. Lotfy M, Adeghate $\mathrm{J}$, Kalasz $\mathrm{H}$, et al. Chronic complications of diabetes mellitus: a mini review. Curr Diabetes Rev 2017;13:3-10.

4. World Health Organization. Global report on diabetes. Geneva: World Health Organization, 2016.

5. Lindström J, Peltonen M, Eriksson JG, et al. Improved lifestyle and decreased diabetes risk over 13 years: long-term follow-up of the randomised finnish diabetes prevention study (DPS). Diabetologia 2013;56:284-93.

6. Knowler WC, Fowler SE, Hamman RF, et al. 10-year follow-up of diabetes incidence and weight loss in the Diabetes Prevention Program Outcomes Study. Lancet 2009;374:1677-86.

7. Simmons RK, Griffin SJ, Witte DR, et al. Effect of population screening for type 2 diabetes and cardiovascular risk factors on mortality rate and cardiovascular events: a controlled trial among 1,912,392 Danish adults. Diabetologia 2017;60:2183-91.

8. Tawfik MY. The impact of health education intervention for prevention and early detection of type 2 diabetes in women with gestational diabetes. J Community Health 2017;42:500-10.
9. KhalafMM A, Eid MM, Najjar HA, et al. Screening for diabetes in Kuwait and evaluation of risk scores. http://apps.who.int/iris/ bitstream/10665/117964/1/16_7_2010_0725_0731.pdf (accessed 30 Dec 2016).

10. Chen L, Magliano DJ, Balkau B, et al. AUSDRISK: an australian type 2 diabetes risk assessment tool based on demographic, lifestyle and simple anthropometric measures. Med J Aust 2010;192:197-202.

11. Glümer C, Carstensen B, Sandbaek A, et al. A Danish diabetes risk score for targeted screening: the Inter99 study. Diabetes Care 2004;27:727-33.

12. Griffin SJ, Little PS, Hales CN, et al. Diabetes risk score: towards earlier detection of type 2 diabetes in general practice. Diabetes Metab Res Rev 2000;16:164-71.

13. Memish ZA, Chang JL, Saeedi MY, et al. Screening for type 2 diabetes and dysglycemia in saudi arabia: development and validation of risk scores. Diabetes Technol Ther 2015;17:693-700.

14. Sulaiman N, Albadawi S, Abusnana S, et al. Novel approach to systematic random sampling in population surveys: Lessons from the United Arab Emirates National Diabetes Study (UAEDIAB). $J$ Diabetes 2015;7:642-8.

15. World Health Organization. Definition, diagnosis and classification of diabetes mellitus and its complications: report of a who consultation. part 1: diagnosis and classification of diabetes mellitus. Geneva: World Health Organization, 1999.

16. World Health Organization. Use of glycated hemoglobin (HbA1c) in the diagnosis of diabetes mellitus abbreviated report of a WHO consultation. Geneva: World Health Organization, 2011.

17. Ng SW, Zaghloul S, Ali HI, et al. The prevalence and trends of overweight, obesity and nutrition-related non-communicable diseases in the Arabian Gulf States. Obes Rev 2011;12:1-3.

18. Al-Nozha MM, Al-Maatouq MA, Al-Mazrou YY, et al. Diabetes mellitus in Saudi Arabia. Saudi Med J 2004;25:1603-10.

19. Al-Lawati JA, Tuomilehto J. Diabetes risk score in Oman: a tool to identify prevalent type 2 diabetes among Arabs of the Middle East. Diabetes Res Clin Pract 2007;77:438-44.

20. Wang A, Chen G, Su Z, et al. Risk scores for predicting incidence of type 2 diabetes in the Chinese population: the Kailuan prospective study. Sci Rep 2016;6:26548.

21. Aekplakorn W, Bunnag P, Woodward M, et al. A risk score for predicting incident diabetes in the Thai population. Diabetes Care 2006;29:1872-7.

22. Lindström J, Louheranta A, Mannelin M, et al. The finnish diabetes prevention study (DPS): lifestyle intervention and 3-year results on diet and physical activity. Diabetes Care 2003;26:3230-6. 